\title{
PEMAHAMAN GURU TERHADAP STANDAR ISI SEKOLAH LANJUTAN TINGKAT PERTAMA KOTA BANDUNG
}

\begin{tabular}{lll}
\hline Received: 05-02-2020 & Revised: 18-06-2020 Accepted: 30-07-2020 \\
\hline Umniyatul Azizah ${ }^{1}$, Chairul Rahman ${ }^{2}$, Ida Farida ${ }^{3}$, Nina Nurmilasari \\
Universitas Islam Negeri Sunan Gunung Djati Bandung 1234 \\
Email: umniyatulazizah@gmail.com, chaerulrochman99@uinsgd.ac.id \\
\end{tabular}

\section{Keywords:}

Islamic Religious

Education (IRE) ;

Content

Standards; The

Constitution of 1945.

\begin{abstract}
This study aims to explain a comparative analysis of the content standards among 5 PAI teachers (Teacher of Islamic Education) and 5 Non PAI teachers (Not the Teacher of Islamic Education), and to find out the legal basis for the content standards and then note on each indicator appears. The method used in this research is the descriptive quantitative method. The population of this research is Junior (Islamic) High School (SMP/MTS) in Bandung. The data collection techniques applied in this research are observation, questionnaire, documentation, and data analysis. Retrieval of data and observation which used is google form that was distributed to 5 PAI teachers and 5 Non-IRE (Islamic Religious Education) teachers. The result of collecting authentic data and data triangulation through interviews with teachers and through comparative data analysis between IRE and Non-IRE shows that from 5 points presented by the researcher, PAI is superior in 3 points, while Non-IRE is superior in 2 points.
\end{abstract}

Abstrak
Penelitian ini bertujuan memaparkan analisis perbandingan
standar isi dari 5 guru PAI dan Non PAI dan menemukan
dasar hukum standar isi lalu diperhatikan setiap indikator.
Metode yang digunakan dalam penelitian ini adalah metode
kuantitatif deskriptif. Sebagai penelitian terdahulupun belum
ada yang menganalisis perbandingan Standar Isi guru PAI
dan Non PAI sebagai bentuk acuan dari pemerintah. Adapun
peneliti mengambil 5 sample guru PAI dan 5 sample guru non
PAI. Populasi pada penelitian ini adalah 50 orang guru
SMP/MTs kota Bandung dan dipilih sampel sebanyak 5 orang
guru PAI dan 5 orang guru Non PAI. Teknik pengumpulan
data menggunakan kuesioner dan analisis data wawancara
triangulasi. Pengambilan data dan kuesioner menggunakan
google form yang disebar disetiap 5 guru PAI dan 5 guru Non
PAI. Mengumpulkan data otentik dan triangulasi hasil
wawancara dengan beberapa guru yang mana diambil dari
pengisian google form, dari data yang terendah dan tertinggi,

http://pasca.jurnalikhac.ac.id/index.php/tijie/index

\begin{tabular}{l} 
Kata kunci: \\
Pendidikan \\
Agama Islam \\
(PAI); Standar isi; \\
UUD 1945. \\
\hline
\end{tabular}


juga menganalisis hasil perbandingan antara PAI dan Non PAI, maka 3 point PAI lebih unggul dan Non PAI 2 point lebih unggul dari 5 point yang disajikan oleh peneliti.

\section{PENDAHULUAN}

Komponen pendidikan sistem standarisasi pemahaman terhadap standar isi merupakan salah satu komponen yang sangat penting dalam pendidikan, yang mana standar isi pendidikan saat ini belum merata, termasuk oleh para tenaga pendidik dan kependidikan. Kebijakan pemerintah tentang standar pendidikan menjadi salah satu komptensi yang dimiliki oleh segenap tenaga pendidik. Namun, masih banyak yang belum memahami dan mengimplementasikan standard tersebut dalam tugas seharihari yang diharapkan oleh masyarakat. ${ }^{1}$

Pendidikan di Indonesia berlandaskan Pancasila dan Undang-Undang Dasar 1945 yang bertujuan mengembangkan semanpuan dan menyiapkan pribadi serta peradaban bangsa yang bermartabat dalam rangka tujuan untuk mencerdaskan Bangsa Indonesia. ${ }^{2}$ Dalam hal ini peserta didik mampu menjadi apa yang diharapkan melalui terbinanya pendidikaan dari dalam dokumen standar isi sebagaimana yang dimaksud oleh peraturan pemerintah No. 19 tahun 2005, yang secara garis besar mencakup dari kerangka dasar dan struktur kurikulum yang merupakan pedoman dalam penyusunan kurikulum tentang satuan pendidikan, beban belajar begi peserta didik pada satuan dasar dan menengah, kurikulum tingkat satuan pendidikan yang akan dikembangkan oleh satuan pendidikan berdasarkan panduan penyusunan kurikulum sebagai bagian tidak terpisahkan dari satandar isi dan kalender pendidikan untuk penyelenggaraan pendidikan pada satuan pendidikan jenjang pendidikan dasar dan menengah. Standar isi dikembangkan oleh Badan Standar Nasional Pendidikan (BSNP) yang di bentuk berdasarkan Perturan Pemerintah Nomor 19 tahun 2005 (SPMI, 2016). ${ }^{3}$

${ }^{1}$ F. Jaya, A., S. and Ellyawati, "Implementasi Standar Nasional Pendidikan Di Kabupaten Aceh Besar Suatu Persepsi Dan Harapan Masyarakat," Jurnal Dedikasi Pendidikan 3, no. 1 (2019): $1-13$.

2 Sukardi, Evaluasi Program Pendidikan Dan Pelatihan (Jakarta: Bumi Aksara, 2015).

${ }^{3}$ Kalluri Subba Rao, “PERMENRISTEKDIKTI_Nomor_44_Tahun_2015_SNPT / Standards of Higher Education," Current Science 97, no. 9 (2009): 1276. 
Terkait dengan beberapa kebijakan standard isi di atas. Ada beberapa penelitian yang telah dilakukan terkait dengan pemahaman dan implementasi standard isi dalam proses pendidikan di sekolah. Seperti Alawiyah ${ }^{4}$ menyimpulkan bahwa masih banyak guru yang belum memahami cara menerapkan standar isi pada proses pembelajaran. Demikian pula hasil riset beberapa jurnal menyimpulkan bahwa salah satu faktor lemahnya implementasi standard isi adalah menguraikan indikatorindikator standar isi ${ }^{5}$. Berdasarkan informasi dan temuan-temuan tentang standard isi di atas, maka pentinglah dilakukan pengkajian atau penelitian atau penelusuran tentang pemahaman guru terhadap standard isi. Tujuan penelitian ini adalah untuk mengungkap dan mengkaji pemahaman standard isi dari guru PAI dan guru NonPAI.

Sebagaimana telah ditegaskan dalam undang-undang, wajib mengembangkan perangkat pembelajaran dalam satuan pendidikan pada kompetensi inti meliputi spiritual, sosial, pengetahuan dan keterampilan 6 . Sekolah juga harus mengembangkan perangkat pembelajaran Agama Islam dan budi pekerti. ${ }^{7}$ Dalam proses pembentukan akhlak mulia, pendidikan agama adalah hal yang sangat penting karenanya membentuk akhlak mulia sama dengan membentuk kepribadian muslim. Selain itu, pembelajaran tematik yang terintegrasi pada setiap jenjang kelas juga berupaya agar guru-guru dapat mengembangkannya. Disamping itu, sekolah menggunakan Kurikulum 2013 dan menerapkannya kurikulum sesuai dengan tahapannya dengan

\footnotetext{
4 Faridah Alawiyah, "Standar Nasional Pendidikan Dasar Dan Menengah," Aspirasi 8, no. 1 (2017): 81-92.

5 Sudarsri Lestari, "Analisis Standar Pendidik Dan Tenaga Kependidikan (Studi Di Sdn 3 Tamanagung Banyuwangi)," Nidhomul Haq : Jurnal Manajemen Pendidikan Islam 3, no. 1 (March 30, 2018): 18-22, https://doi.org/10.31538/nidhomulhaq.v3i1.106.

6 Dania Evirianti, Irawan Suntoro, and Yunisca Nurmalisa, "Studi Komparatif Kompetensi Pedagogik Guru Pkn Berdasarkan Latar Belakang Pendidikan," Jurnal Kultur Demokrasi 2, no. 4 (April 17, 2014), http://jurnal.fkip.unila.ac.id/index.php/JKD/article/view/4495; Shalahudin Ismail et al., "The Competence of Millennial Islamic Education Teachers in Facing The Challenges of Industrial Revolution," Nazhruna: Jurnal Pendidikan Islam 3, no. 3 (November 4, 2020): 389-405, https://doi.org/10.31538/nzh.v3i3.823; Auli Toom, Jukka Husu, and Kirsi Tirri, "Cultivating Student Teachers? Moral Competencies in Teaching during Teacher Education," in International Teacher Education: Promising Pedagogies (Part C), vol. 22C, 0 vols., Advances in Research on Teaching 22C (Emerald Group Publishing Limited, 2015), 11-31, https://doi.org/10.1108/S1479-368720150000026001.

7 Zulfitria, "PERANAN PEMBELAJARAN TAHFIDZAL-QURAN DALAM PENDIDIKAN KARAKTER DI SEKOLAH DASAR," Naturalistic: Jurnal Kajian Penelitian Pendidikan Dan Pembelajaran 1, 2, 2017, 124-43.
} 


\section{Umniyatul Azizah et al}

melibatkan steackholder dan melaksanakan kurikulum sesuai dengan ketentuan juga merupakan tugas dari sekolah. 8

Dalam pendidikan sejatinya guru bukan hanya sekedar mentransfer pengetahuan (knowledge) dari pemikiran pendidik ke pesarta didik, namun juga pendidik harus membimbing dari ranah afektif dan psikomotornya kepada peserta didik $^{9}$. Pendidik menjadi teladan bagi peserta didiknya yang perlu dimuat dalam standar isi, termasuk bersama-sama membangun karsa dengan peserta didiknya dan menjadi pendorong bagi peserta didik kelak di waktu yang akan datang. Sebagai subjek belajar dalam pembelajaran peserta didik harus dilibatkan secara aktif agar tujuan dari standar isi tercapai, hal ini juga berlaku bagi kegiatan yang ditempuh peserta didik dengan giat dan semangat dalam mengikuti pembelajaran dan tidak menyebabkan kejenuhan dalam belajar. ${ }^{10}$

Pendidik juga harus berfikir keritis dalam menghadapi perkembangan zaman khususnya zaman modern seperti sekarang, dengan menyampaikan standar isi dengan mengikuti perkembangan zaman yang ada, sehingga singkron terhadap peserta didik, untuk itu ciri - ciri dari pendidik yang berpikir kritis yakni antara lain: (1) memberikan pernyataan dan pertanyaan yang jelas dari maksud dan arti yang akan diajarkan oleh peserta didik, (2) mencari tau dasar atau argument yang kuat pada setiap pernyataan, (3) mencari tahu informasi terupdate, (4) membiasakan dalam menggunakan dan menyebutkan sumber dari pengetahuan yang akan dipelajari, (5) memberikan penempatan di situasi dan kondisi yang tepat, (6) relevan terhadap pokok pembicaraan yang dibahas dalam pembelajaran, (7) memiliki banyak alternatif, (8) memiliki pertimbangan di awal dan akhir dalam pembelajaran, (9) memiliki sifat

8 Luthfiyyah Saajidah, "Fungsi-Fungsi Manajemen Dalam Pengelolaan Kurikulum," Madrasa: Journal of Islamic Educational Management 1, no. 2 (2018): 16-22, https://doi.org/10.32940/mjiem.v1i0.71.

${ }^{9}$ Muhammad Anas Ma'arif, "Analisis Konsep Kompetensi Kepribadian Guru PAI Menurut AzZarnuji," ISTAWA 2, no. 2 (2017): 35-60; Inok Ahn, Ming Ming Chiu, and Helen Patrick, "Connecting Teacher and Student Motivation: Student-Perceived Teacher Need-Supportive Practices and Student Need Satisfaction," Contemporary Educational Psychology 64 (January 1, 2021): 101950, https://doi.org/10.1016/j.cedpsych.2021.101950; Ayu Asmarani, Sukarno Sukarno, and Minnah El Widdah, "The Relationship of Professional Competence with Teacher Work Productivity in Madrasah Aliyah," Nidhomul Haq: Jurnal Manajemen Pendidikan Islam 6, no. 2 (July 2, 2021): 220-35, https://doi.org/10.31538/ndh.v6i2.1365.

10 Hasbullah, Juhji, and Ali Maksum, "Strategi Belajar Mengajar Dalam Upaya Islam," Journal Prndidikan Agama Islam Edureligia 3, no. 1 (2019): 17-24. 
terbuka, (10) mengambil tindakan yang tepat saat merubah posisi pembelajaran apabila terdapat kekeliruan, (11) teliti dan tepat, (12) berurutan sampai menjadi kompleks, (13) menggunakan kemampuan berfikir keritis dan tekun, (14) peka dengan perasaan peserta didik, peka terhadap pemikiran peserta didik dan kritisnya berbeda, dan (15) mampu mencari tahu pemikiran kritisnya peserta didik.11

Peneliti tertarik meneliti standar isi ini karena mengharapkan pencapaian yang seimbang antara guru PAI dan guru Non PAI karena PAI itu sendiri harus bisa menyesuaikan dengan perkembangan zaman yang ada, situasi serta kondisi yang dianalisis di Kota Bandung tingkat SMP/Mts. Tujuan dari penelitian ini adalah mengetahui sejauhmana perbandingan pengetahuan Standar Isi disekolah guru PAI dan guru Non PAI.

\section{METODE PENELITIAN}

Dalam penelitian ini, peneliti menggunakan metode kuantitatif deskriptif. Dimana penelitian kuantitaf deskriptif ini mengumpulkan angket kemudian dideskripsikan, adapun tambahan metode tambahan lainnya yaitu menggunakan kuesioner, yakni menggunakan google form, kuesioner ini dilakukan secara online. Penelitian ini menetapkan Populasi sebanyak 5 guru PAI dan 5 guru Non PAI sebagai dasar dalam mengembangkan penelitian yang dibagi pada tingkat SMP/MTs di kota Bandung. Adapun peneliti menggunakan teknik observasi, angket dan analisis data sebagai alat bantu dalam memudahkan penelitian ini.setelah proses memasukan standar isi kedalam google form, peneliti membagikan lewat situs kepada guru-guru yang megajar PAI dan ilmu umum sebanyak 5 orang 5 orang, dengan memiliki alternaatif jawaban sebanyak 4 butir pada setiap soal instrument yang di berikan oleh peneliti dan selanjutnya peneliti menentukan skor. lalu peneliti mendapatkan hasil kembali dan di olah menjadi sebuah data kuantitatif dan dideskripsikan sebagai alat ukur untuk mengambil kesimpulan. Adapun sebagai instrument dalam penelitian, peneliti berpatokan pada standar isi SMP/MTs. Penelitian ini memaparkan pemahaman guru terhadap Standar Isi melalui perhitungan presepsi guru terhadap setiap indikator.

${ }^{11}$ Adila Suardi, "Rofesi Guru Dalam Mengembangkan Kemampuan Berfikir Kritis Peserta Didik Di Era Globalisasi," Profesi Guru Dalam Mengembangkan Kemampuan Berfikir Kritis Peserta Didik Di Era Globalisasi 5, no. 1 (2018): 16-24. 


\section{Umniyatul Azizah et al}

Instrument yang digunakan adalah angket pemahaman terhadap standar isi. Indikator standar isi berjumlah 9 (Sembilan buah indikator, yaitu berisi tentang sikap spiritual, pengetahuan, sikap dan keterampilan. Data dikumpulkan dengan cara memberikan lembar angket melalui google form langsung kepada guru-guru yang bersangkutan. Instrument tersebut berupa : Pada kompetensi sikap spiritual, guru mengembangkan perangkat pembelajaran sesuai dengan tingkat kompetensi siswa, Pada kompetensi sikap sosial, guru mengembangkan perangkat pembelajaran sesuai dengan tingkat kompetensi siswa, Pada kompetensi pengetahuan, guru mengembengkan perangkat pebelajaran, sesuai dengan tingkat kompetensi siswa, Pada kompetensi keterampilan, guru mengembangkan perangkat pembelajaran sesuai dengan tingkat kompetensi yang siswa miliki, Tingkat kompetensi dan ruang lingkup materi pembelajaran pada setiap tingkat kelas, Sekolah/madrasah mengembangkan perangkat pembelajaran dengan sesuai.

Adapun tahapan-tahapan dalam mengolah dan menganalisis data adalah dilakukan dengan cara sebagai berikut : (1) membuat setiap komponen indikator menggunakan google form (2) menyebar angket dengan disediakan link oleh google form terhadap guru-guru PAI dan Non PAI (3) pertanyaan yang berisi komponen 10 indikator akan dikirimkan langsung jawabannya kepada peneliti (4) hasil tersebut diolah menjadi data kuantitatif lalu dideskripsikan sebagai alat ukur untuk penarikan kesimpulan. ${ }^{12}$

\section{HASIL PENELITIAN DAN PEMBAHASAN}

Hasil pengolahan data terhadap pemahaman guru tentang standar isi pada SMP/MTs kota Bandung, maka berikut ini disajikan pembahasan tentang Profil Pemahaman standar isi Guru PAI dan Non PAI berdasarkan Indikator, Profil Pemahaman Standar Isi berdasarkan kelompok guru dan terakhir triangulasi dengan teknik wawancara.

\section{Profil Pemahaman Standar Isi Berdasarkan Indikator}

Profil pemahaman standar isi berdasarkan 10 indikator dapat disajikan melalui diagram batang berikut ini.

12 D E Kusumaningrum, I Arifin, and ..., "Pendampingan Pengembangan Perangkat Pembelajaran Berbasis Kurikulum 2013," ... PEDAGOGI: Jurnal Ilmiah ..., no. 1 (2017): 16-21. 


\section{Profil Pemahaman Standar Isi Berdasarkan}

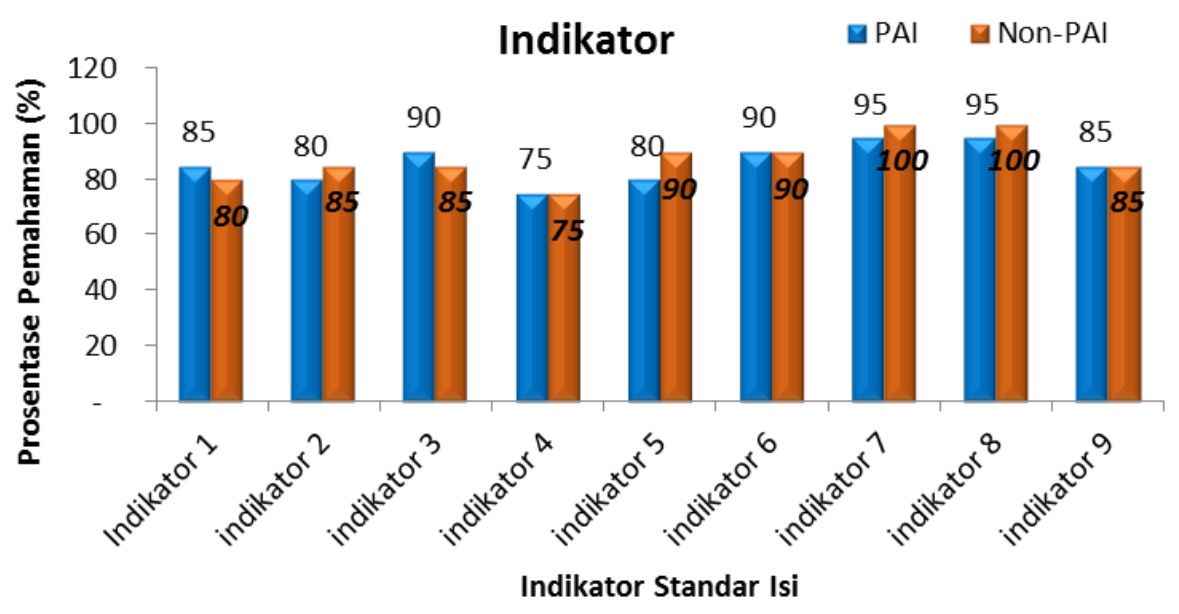

Grafik 1. Profil Pemahaman Standar Isi

Dari Grafik 1 diatas menunjukkan bahwa profil pemahaman standard isi berdasarkan indicator bervariasi. Kedua kelompok Guru PAI maupun Non PAI prosentase pemahaman terbesar terletak pada indikator 7 dan 8 . Indikator tersebut berkaitan dengan komponen KTSP dan tahapan pengembangan KTSP. Sedangkan indikator yang paling rendah untuk kedua kelompok terletak pada indikator nomor 4, yaitu tentang kemampuan guru dalam mengembangkan perangkat pembelajaran.

Dalam meningkatkan mutu pembelajaran hendaklah falsafah dan metodologi dalam pembelajaran hendaklah selalu di mutakhirkan, dikembangkan serta diperbaharui. Untuk itu pendidik hendaklah mempertimbangkan segala falsafah dan metologi dalam proses pembelajaran agar pendidikan semakin berkualitas dan membuka pikiran para pendidik. Dalam mendidik guru dituntut pula untuk memiliki pengetahuan yang luas agar memudahkan pendidik dalam menyampaikan pembelajaran terhadap peserta didik, untuk itu pendidik harus mengerti perubahan perkembangan zaman sesuai dengan kebutuhan peserta didik. ${ }^{13}$

Profil pemahaman guru terhadap standar isi terlihat masih lemah pada indikator kemampuan dalam mengembangkan perangkat pembelajaran. Hal ini

\footnotetext{
13 Ibid

Hasbullah, Juhji, and Maksum, "Strategi Belajar Mengajar Dalam Upaya Islam."
} 


\section{Umniyatul Azizah et al}

sejalan dengan hasil penelitian yang dilakukan oleh Desi Rahmawati (2017), ${ }^{14}$ bahwa guru masih memiliki kesulitan dalam melengkapi perangkat pembelajaran. Demikian pula Ikhwan (2015) meyakini bahwa salah satu kelemahan guru dalam administrasi pembelajaran terletak kepada belum mampunya guru mengembangkan rencana pelaksanaan pembelajaran (RPP). ${ }^{15}$ Sedangkan guru PAI maupun Non PAI mereka sudah memiliki kecencerungan memahami komponen KTSP. Seperti temuan yang dilakukan oleh Alawiyah (2017).16 Bahwa sebagian besar guru dalam satu sekolah sudah mengenal komponen KTSP. Demikian pula guru sudah mengetahui bahwa KTSP penting untuk dikembangkan. Namun sebagian peneliti menemukan masih ada guru yang mengerti komponen KTSP, tetapi belum menguasai cara pengembangan. Adapun buku juga menjadi salah satu pengantar standar isi dalam dunia pendidikan untuk mencapai kompetensi yang diharapkan. standar isi ini harus memiliki kesesuaian dengan buku mata pelajaran karena untuk mendukung komptensikompetensi dari peserta didik hingga ia dapat memahami buku pelajaran untuk mencapai standar isi yang di sajikan oleh sekolah itu tersebut. ${ }^{17}$

Berdasarkan informasi di atas, maka masalah utama yang dihadapi oleh guru PAI maupun guru Non PAI adalah kelemahan dalam mengembangkan perangkat pembelajaran. Kelemahan ini mungkin diakibatkan oleh jarangnya guru mendapatkan pelatihan pedagogik maupun keterampilan administrasi. Jika guru mendapatkan pelatihan pedagogik secara bertahap dan teratur maka guru akan jauh lebih mengerti dalam memahami keterampilan ini. Dan kesesuain buku terhadap standar isipun harus dipenuhi agar peserta didik dapat memahami kompetensi-kompetensi yang akan didapatkan.

${ }^{14}$ Desi Rahmawati and Arlyta Dwi Anggraini, "Evaluasi Program Kurikulum Berdasarkan Standar Isi, Standar Proses, Dan Standar Kompetensi Lulusan Di Sdn Pisangan Timur 10 Pagi," Jurnal Pendidikan Ekonomi Dan Bisnis (JPEB) 5, no. 1 (2017): 34, https://doi.org/10.21009/jpeb.005.1.3.

15 Wahid Khoirul Ikhwan, "Implementasi Standar Isi, Standar Proses, Standar Lulusan Sebagai Standar Mutu Pendidikan MTs Negeri Di Kabupaten Tulungagung," PEDAGOGIA: Jurnal Pendidikan 4, no. 1 (2015): 16, https://doi.org/10.21070/pedagogia.v4i1.68.

${ }^{16}$ Alawiyah, loc.it., hlm 2-12.

Alawiyah, "Standar Nasional Pendidikan Dasar Dan Menengah."

17 Apolonia Hendrice et al., "Analisis Kesesuaian Standar Isi Buku Teks Matematika Kelas VIII Dengan Kurikulum 2013," Jurnal Eksata Pendidikan 2, no. November (2018): 162-69. 


\section{Perbandingan Prosentase Pemahaman Standar Isi}

Perbandingan prosentase pemahaman standar isi berdasarkan responden guru PAI dan Non PAI dapat disajikan melalui grafik berikut ini.

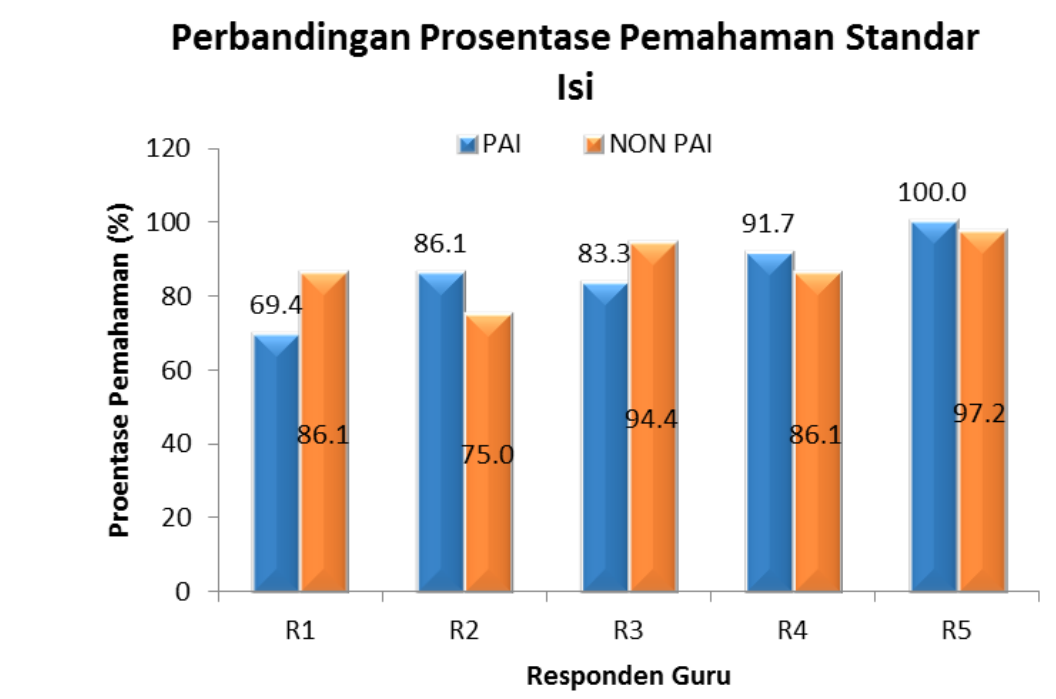

Grafik 2. Perbandingan prosentase pemahaman standar isi

\section{Perbandingan Rata-rata Pemahaman \\ Standar Isi}

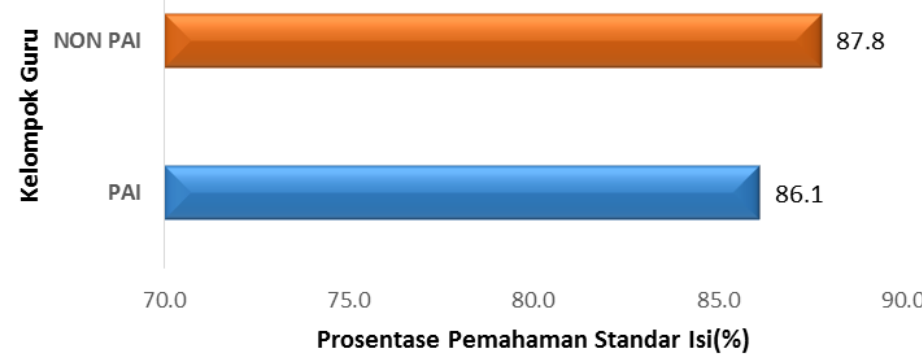

Grafik 3. Perbandingan rata-rata prosentase standar isi Guru PAI dan Non PAI

Pada Grafik 2 perbandingan prosentase pemahaman standar isi dan Grafik 3 menunjukkan bahwa perbandingan pemahaman standard isi berdasarkan kelompok guru terlihat bervariasi. Responden pada kelompok Guru PAI diperoleh oleh Responden kelima, yaitu 100\%. Sedangkan prosentase terrendah adalah Responden pertama, yaitu 69,4\%. Responden pada kelompok Guru Non PAI diperoleh oleh Responden kelima, yaitu 97,2\%. Sedangkan prosentase terrendah adalah Responden 


\section{Umniyatul Azizah et al}

kedua, yaitu 75\%. Sedangkan grafik 3 menunjukkan rata-rata prosentase pemahaman standard isi kelompok guru PAI dan Non PAI. Prosentase pemahaman standard isi guru Non PAI $(87,8 \%)$ lebih besar di banding dengan guru PAI $(86,1)$

Perbandingan prosentase pemahaman Standar isi ini berdasarkan kelompok guru, terlihat pada guru Non PAI $(87,8)$ karena setengah dari guru memahami capaian dari standar isi tersebut, hal ini sesuai dengan penelitan (Munaris, 2018) ${ }^{18}$. Sedangkan kelompok guru PAI masih kurang $(86,1)$ dalam memahami standar isi, meskipun dalam kategori baik, namun tetap saja mengalami beberapa kesulitan dalam pengembangan perangkat pembelajaran disekolah. ${ }^{19}$

Masalah utama yang dapat disimpulkan dari informasi diatas adalah kelemahan dalam mengembangkan perangkat pembelajaran PAI dan mengembangkan KTSP baik dari kelompok guru PAI maupun kelompok guru Non PAI. Hal ini disebabkan karena kurangnya pelatihan pedagogik maupun keterampilan administrasi. Agar guru semakin siap dalam megikuti pelatihan dan meningkatkan kinerjanya. Pelatihan ini dapat berdampak pada hasil belajar peserta didik agar menjadi lebih baik. ${ }^{20}$

Pada prosentase dari analisis diatas dalam penelitian ini menerapkan Triangulasi. Tujuan triangulasi yaitu untuk mendapatkan jawaban mendalam dari guru PAI dan Non PAI. Cara mendapatkan hasil dari triangulasi yaitu dengan wawancara pada guru PAI dan guru Non PAI. Adapun responden 1 orang dari guru PAI dan 1 orang lagi dari guru non PAI. Pada indikator 4 terdapat permasalahanpermaslahan yang dihadapi dalam penyampaian standar isi, diantaranya kurangnya buku paket, guru kurang memodifikasi cara penyampaian disekolah, konsentrasi siswa rendah, guru yang mengajar tidak sesuai dengan jurusan dan lain-lain, sedangkan pada indikator 9 dikarenakan kurang updatenya guru tentang pengetahuan kurikulum sehingga untuk menjdikan kualitas dari standar isi maka menurut beberapa

18 Munaris Munaris and Bambang Riadi, "Pemahaman Guru Bahasa Indonesia SMA Di Kabupaten Mesuji Terhadap Kurikulum 2013 Edisi Revisi," AKSARA: Jurnal Bahasa Dan Sastra 19, no. 1 (2018): 54-60, https:/ / doi.org/10.23960/aksara/v19i1.pp54-60.

19 Adi Sumarsono, "Persepsi Guru Madrasah Ibtidaiyah ( Mi ) Dalam Menerapkan Kurikulum 2013 Di Kabupaten Merauke," Jurnal Al-Ishlah: Jurnal Pendidikan 10, no. 2 (2018): 156-70.

${ }^{20}$ Euis Rosita et al., "Pencapaian Standar Isi: Tantangan Bagi Guru Madrasah," NATURALISTIC : Jurnal Kajian Penelitian Pendidikan Dan Pembelajaran 5, no. 1 (2020): 627-34, https://doi.org/10.35568/naturalistic.v5i1.819. 
referensi yang sudah dicantumkan diatas adalah dengan melakukannya pelatihanpelatihan terhadap guru agar semakin baik lagi pelaksanaan di sekolah, adapun jika siswa kurang memperhatikan silakan lakukan metode yang tepat dalam melaksanakan pendidikan. Untuk lebih jauh peneliti menguraikan beberapa pertanyaan. Pertanyaan itu adalah 1) Penyebab dari mengapa indikator tersebut rendah atau kurangnya dalam menerapkan indicator tersebut dan 2) Cara untuk meningkatkan indikator tersebut menurut bapa dan ibu guru. ${ }^{21}$

Hasil triangulasi didapatkan dari hasil data terendah dan tertinggi kemudian dilakukan teknik wawancara, wawancara yakni digali untuk mendapatkan informasi, pendapat, tanggapan ataupun motivasi seseorang dengan cara proses tanya jawab dengan tatap muka atau tidak, contohnya dengan menggunakan virtual. Dalam wawancara terdapat sedikitnya 2 (dua) belah pihak yang masing-masing punya kedudukan yang berbeda. Yang satu sebagai pencari informasi dan salah seorang atau yang lainnya sebagai responden (yang memberi informasi).22 Artikel ini memuat wawancara secara virtual, yang mengambil responden terendah dan tertinggi dari kuesioner, yang selanjutnya dilakukan triangulasi, dengan hasil sebagai berikut:

Pada responden PAI indikator terendah terdapat pada R1 (RZ) Guru PAI di salah satu SMP yang ada di Purwakarta. Ia mengemukakan penyebab dari indikator 4 adalah dari sekolah dan dari siswa itu sendiri siswa itu sendiri: dari pihak sekolah kurangnya fasilitas seperti buku paket dan media ataupun bahan ajar, dari pihak gurupun banyak yang mengajar tidak sesuai jurusan seingga kurannya KBM, sedangkan, dari faktor siswa kurang konsentrasi saat diberikan pembelajaran dan mengganggu teman-teman yang lain. Menurut R1, untuk meningkatkan, KBM harus memadai, fasilitas sekolah juga harus memedai dan siswa harus bisa memengami dengan menanamkan sikap yang sungguh-sungguh dalam belajar.

Selanjutnya, pada responden PAI terendah terdapat pada R1 (RZ) namun kali ini terdapat pada indikator 9, penyebab dari indikator rendah tersebut menurut

${ }^{21}$ Ibid.

Munaris and Riadi, "Pemahaman Guru Bahasa Indonesia SMA Di Kabupaten Mesuji Terhadap Kurikulum 2013 Edisi Revisi."

${ }^{22}$ MS, Soegijono, "Wawancara Sebagai Salah Satu Metode Pengumpulan Data," Media Penelitian Dan Pengembangan Kesehatan 3, no. 1 (1993): 17-21, https://doi.org/10.22435/mpk.v3i1.930. 


\section{Umniyatul Azizah et al}

responden karena prosesnya guru hampir tidak sesuai dengan kurikulum sebab guruguru yang sudah lumayan lama mengajar hanya menggunakan kurikulum yang sudah ada sebelumnya saja, jadi gurunya kurang update dan menggunakan keterampilan yang terdahulu secara berulang. Adapun menurut R1, untuk meningkatkan, guru harus paham dan mengerti baik dengan cara mencari tau atau meminta bantuan dengan guru lain sehingga kurikulum terbantu, apalagi zaman sekarang banyak menggunakan teknologi untuk itu harus paham dulu dari guru untuk keberhasilan KBM disekolah.

Untuk responden guru Non-PAI terdapat pada R2 yang mengabdikan diri di salah satu Madrasah Tsanawiyah yang ada di kota Garut. Ia mengemukakan bahwa penyebab indikator rendah terdapat pada indikator 4. Penyebeb rendahnya adalah karena kurangnya siswa dalam memperhatikan guru, guru kurang bisa ngondisifkan kelas, kembali lagi kurangnya kedisiplinan siswa atau kurang tegasnya guru, metode dan strategi gurupun juga kurang maksimal dalam pembelajaran, dan kurang penguasaan materi, kurang persiapan, sehingga siswa kurang memahami apa yang disampaikan, berakibat pula pada hasil belajar yang kurang baik. Adapun untuk meningkatkannya, dengan cara, terus memperbaiki kualitas ilmu yang dimiliki guru, kemudian metode yang digunakan difahami dan dikembangkan, diterapkan kedisiplinan dan diadakannya evaluasi pembelajaran

Berdasarkan hasil triangulasi diatas, menunjukan performasi indikator-indikator yang tergolong rendah yaitu indikator 4 dan indikator 9, rata-rata karena kurangnya pengetahuan tentang standar isi dan cara untuk menerapkannya dengan baik disekolah, adapun standar isi harus difahami secara rinci untuk kualifikasi terbaik dari indikator dan dikehendaki.23 Solusi dalam standar isi ini adalah baiknya dengan mengadakan pelatihan secara berkala agar guru dan calon guru benar-benar memahami ketercapaian pada standar isi ini.

23 Ani Jailani and Chaerul Rochman, "Analisis Ketercapaian Standar Isi Pada Sekolah Dasar (SD.S Plus Syania Kec. Cimanggung Kab. Sumedang Jawa Barat)," JIP: Jurnal Ilmiah PGMI 5, no. 1 (2019): 74-83, https://doi.org/10.19109/jip.v5i1.3183. 


\section{KESIMPULAN}

Berdasarkan analisis penyajian data dan pemahaman terhadap standar isi kelompok guru PAI dan kelompok guru Non-PAI, dapat disimpulkan bahwa kurang updatenya pemahaman terhadap standar isi sehingga guru-guru lebih banyak menggunakan standar isi terdahulu disebabkan faktor usia dan malasnya mencari tahu updatean standar isi terbaru. Masalah ini terjadi karena guru-guru jarang mengikuti pelatihan-pelatihan yang berhubungan dengan sekolah, meningkatkan kinerja dan pengembangan kurikulum. Semua guru harus terlibat aktif mulai dari perencanaan, pelaksanaan serta evaluasi guna memperbaiki pendidikan yang akan datang.

Standar isi dilihat dari hasil PAI dan Non PAI memiliki hasil yang berbeda, namun tidak terlalu signifikan, dapat dilihat dari diagram terakhir responden 1 Non PAI lebih unggul, responden 2 PAI lebih unggul, responden ke 3 Non PAI lebih unggul, responden 4 PAI lebih unggul dan responden ke 5 PAI lebih unggul. Jadi lebih unggul 3 PAI dan 2 Non PAI berdasarkan dari perbandingan 5 Responden. Walaupun demikian jika dilihat perbandingan rata-rata angka Non PAI lebih memahami Standar Isi yang ada di sekolah SMP/MTs Kota Bandung. Untuk itu dalam meningkatkan kualitas pembelajaran standar isi pendidikan, hendaknya guru dan sekolah bekerja sama untuk melakukan pelatiahan-pelatihan dampaknya agar menciptakan peserta didik yang cemerlang dikemudian hari.

\section{REFERENSI}

Ahn, Inok, Ming Ming Chiu, and Helen Patrick. “Connecting Teacher and Student Motivation: Student-Perceived Teacher Need-Supportive Practices and Student Need Satisfaction." Contemporary Educational Psychology 64 (January 1, 2021): 101950. https://doi.org/10.1016/j.cedpsych.2021.101950.

Alawiyah, Faridah. "Standar Nasional Pendidikan Dasar Dan Menengah." Aspirasi 8, no. 1 (2017): 81-92.

Asmarani, Ayu, Sukarno Sukarno, and Minnah El Widdah. "The Relationship of Professional Competence with Teacher Work Productivity in Madrasah Aliyah." Nidhomul Haq : Jurnal Manajemen Pendidikan Islam 6, no. 2 (July 2, 2021): 220-35. https:// doi.org/10.31538/ndh.v6i2.1365. 


\section{Umniyatul Azizah et al}

Evirianti, Dania, Irawan Suntoro, and Yunisca Nurmalisa. "Studi Komparatif Kompetensi Pedagogik Guru Pkn Berdasarkan Latar Belakang Pendidikan." Jurnal Kultur Demokrasi 2, no. 4 (April 17, 2014). http://jurnal.fkip.unila.ac.id/index.php/JKD/article/view/4495.

Hasbullah, Juhji, and Ali Maksum. "Strategi Belajar Mengajar Dalam Upaya Islam." Journal Prndidikan Agama Islam Edureligia 3, no. 1 (2019): 17-24.

Hendrice, Apolonia, Ramda Valeria, Suryani Kurnila, and Ricardus Jundu. “Analisis Kesesuaian Standar Isi Buku Teks Matematika Kelas VIII Dengan Kurikulum 2013." Jurnal Eksata Pendidikan 2, no. November (2018): 162-69.

Ikhwan, Wahid Khoirul. "Implementasi Standar Isi, Standar Proses, Standar Lulusan Sebagai Standar Mutu Pendidikan MTs Negeri Di Kabupaten Tulungagung." PEDAGOGIA: Jurnal Pendidikan 4, no. 1 (2015): 16. https://doi.org/10.21070/pedagogia.v4i1.68.

Ismail, Shalahudin, Ma'mun Zahrudin, Uus Ruswandi, and Erihadiana Erihadiana. "The Competence of Millennial Islamic Education Teachers in Facing The Challenges of Industrial Revolution." Nazhruna: Jurnal Pendidikan Islam 3, no. 3 (November 4, 2020): 389-405. https:/ / doi.org/10.31538/nzh.v3i3.823.

Jailani, Ani, and Chaerul Rochman. "Analisis Ketercapaian Standar Isi Pada Sekolah Dasar (SD.S Plus Syania Kec. Cimanggung Kab. Sumedang Jawa Barat)." JIP: Jurnal Ilmiah PGMI 5, no. 1 (2019): 74-83. https://doi.org/10.19109/jip.v5i1.3183.

Jaya, A., S., F., and Ellyawati. "Implementasi Standar Nasional Pendidikan Di Kabupaten Aceh Besar Suatu Persepsi Dan Harapan Masyarakat." Jurnal Dedikasi Pendidikan 3, no. 1 (2019): 1-13.

Kusumaningrum, D E, I Arifin, and ... "Pendampingan Pengembangan Perangkat Pembelajaran Berbasis Kurikulum 2013." ... PEDAGOGI: Jurnal Ilmiah ..., no. 1 (2017): 16-21.

Lestari, Sudarsri. “Analisis Standar Pendidik Dan Tenaga Kependidikan (Studi Di Sdn 3 Tamanagung Banyuwangi)." Nidhomul Haq: Jurnal Manajemen Pendidikan Islam 3, no. 1 (March 30, 2018): 18-22. https://doi.org/10.31538/nidhomulhaq.v3i1.106. 
Ma`arif, Muhammad Anas. “Analisis Konsep Kompetensi Kepribadian Guru PAI Menurut Az-Zarnuji." ISTAWA 2, no. 2 (2017): 35-60.

Munaris, Munaris, and Bambang Riadi. "Pemahaman Guru Bahasa Indonesia SMA Di Kabupaten Mesuji Terhadap Kurikulum 2013 Edisi Revisi." AKSARA: Jurnal Bahasa Dan Sastra 19, no. 1 (2018): 54-60. https://doi.org/10.23960/aksara/v19i1.pp54-60.

Rahmawati, Desi, and Arlyta Dwi Anggraini. "Evaluasi Program Kurikulum Berdasarkan Standar Isi, Standar Proses, Dan Standar Kompetensi Lulusan Di Sdn Pisangan Timur 10 Pagi." Jurnal Pendidikan Ekonomi Dan Bisnis (JPEB) 5, no. 1 (2017): 34. https://doi.org/10.21009/jpeb.005.1.3.

Rosita, Euis, Chaerul Rochman, Ida Farida, and Agus Salim Mansur. "Pencapaian Standar Isi: Tantangan Bagi Guru Madrasah." NATURALISTIC: Jurnal Kajian Penelitian Pendidikan Dan Pembelajaran 5, no. 1 (2020): 627-34. https://doi.org/10.35568/naturalistic.v5i1.819.

Saajidah, Luthfiyyah. "Fungsi-Fungsi Manajemen Dalam Pengelolaan Kurikulum." Madrasa: Journal of Islamic Educational Management 1, no. 2 (2018): 16-22. https://doi.org/10.32940/mjiem.v1i0.71.

Soegijono, MS,. “Wawancara Sebagai Salah Satu Metode Pengumpulan Data." Media Penelitian Dan Pengembangan Kesehatan 3, no. 1 (1993): 17-21. https://doi.org/10.22435/mpk.v3i1.930.

Suardi, Adila. “Rofesi Guru Dalam Mengembangkan Kemampuan Berfikir Kritis Peserta Didik Di Era Globalisasi." Profesi Guru Dalam Mengembangkan Kemampuan Berfikir Kritis Peserta Didik Di Era Globalisasi 5, no. 1 (2018): 16-24.

Subba Rao, Kalluri. “PERMENRISTEKDIKTI_Nomor_44_Tahun_2015_SNPT / Standards of Higher Education." Current Science 97, no. 9 (2009): 1276.

Sukardi. Evaluasi Program Pendidikan Dan Pelatihan. Jakarta: Bumi Aksara, 2015.

Sumarsono, Adi. “Persepsi Guru Madrasah Ibtidaiyah ( Mi ) Dalam Menerapkan Kurikulum 2013 Di Kabupaten Merauke." Jurnal Al-Ishlah: Jurnal Pendidikan 10, no. 2 (2018): 156-70.

Toom, Auli, Jukka Husu, and Kirsi Tirri. “Cultivating Student Teachers? Moral Competencies in Teaching during Teacher Education." In International Teacher 
Umniyatul Azizah et al

Education: Promising Pedagogies (Part C), 22C:11-31. Advances in Research on Teaching 22C. Emerald Group Publishing Limited, 2015. https://doi.org/10.1108/S1479-368720150000026001.

Zulfitria. "PERANAN PEMBELAJARAN TAHFIDZAL-QURAN DALAM PENDIDIKAN KARAKTER DI SEKOLAH DASAR." Naturalistic: Jurnal Kajian Penelitian Pendidikan Dan Pembelajaran 1, 2, 2017, 124-43. 